Brandon Regional Health Authority

\section{ANAESTHETIST POSITION FULL TIME}

Applications are invited for the post of fifth anaesthetist providing comprehensive anaesthetic services in a 326 bed hospital serving as a referral centre for Southwestern Manitoba and Southeastern Saskatchewan. Surgical services include general surgery, peripheral vascular surgery, thoracic surgery, urology, orthopaedics, ophthalmology, obstetrics \& gynaecology, ENT. Anaesthetists are in private practice billing fee-for-service according to the Manitoba Fee Schedule. Applicants should have a Fellowship from the Royal College of Physicjans and Surgeons of Canada or be eligible to write this examination.

If you are interested in this position please submit your application with curriculum vitae, not later than December 15,1998 , addressed to:

\section{Dr. Charles P. Wilson, Chief of Staff Brandon General Hospital 150 McTavish Avenue East Brandon, Manitoba R7A 2 B3 \\ Phone: (204) 726-2120 \\ Fax: (204) 728-0528}

\section{LOCUM TENENS}

Sunnybrook \& Women's College Health Science Centre Sunnybrook Site

The Department of Anaesthesia at Sunnybrook \& Women's College Health Science Centre Sunnybrook Site in Toronto is in need of a Locum Tenens anaesthetist commencing January 1 or July 1, 1999.

The duration of employment may be 6,12 or 18 months. Sunnybrook Health Science Centre is a fully affiliated teaching hospital in the University of Toronto. All types of anaesthetic practice with the exception of obstetrics and pediatrics are available.

Interested individuals must be eligible for licensure in the Province of Ontario.

Further information can be obtained by contacting:

$$
\text { Dr. J. Hugh Devitt }
$$

Head, Department of Anaesthesia

Sunnybrook \& Women's College Health

Science Centre

Sunnybrook Site

2075 Bayview Avenue, Suite M3-200

Toronto, ON M4N 3M5

Telephone: (416) 480-4864

Fax: (416) 480-6039

e-mail:j.hugh_devitt@mail.magic.ca

\title{
ACADEMIC ANAESTHETIST
}

The Department of Anaesthesia at Sunnybrook \& Women's College Health Science Centre Sunnybrook Site in Toronto is in need of full-time academic anaesthetists. Sunnybrook \& Women's College Health Science Centre Sunnybrook Site is a fully affiliated teaching hospital with the University of Toronto. All types of anaesthetic practice with the exception of obstetrics and pediatrics are available.

Academic activities at Sunnybrook \& Women's College Health Science Centre Sunnybrook Site are concentrated in the following areas: 1) cell biology, mechanism of anaesthetic action, 2) critical care medicine, 3) trauma resuscitation and outcomes, 4) cardiovascular diseases, 5) acute and chronic pain management. Preference will be given to proven academic achievement in the above areas. All candidates must be eligible for registration with the College of Physicians and Surgeons of Ontario. For further information, please contact:

\author{
Dr. Hugh Devitt, Head, Department of Anaesthesia \\ Sunnybrook \& Women's College Health Science Centre \\ Sunnybrook Site \\ 2075 Bayview Avenue, Suite M3-200 \\ Toronto, ON M4N 3M5 \\ Telephone: (416) 480-4864 \\ Fax: (416) 480-6039 \\ e-mail:j.hugh_devitt@mail.magic.ca
}

